Frithjof Ehm

\title{
Das völkerrechtliche Demokratiegebot
}

Eine Untersuchung zur schwindenden Wertneutralität des Völkerrechts gegenüber den staatlichen Binnenstrukturen

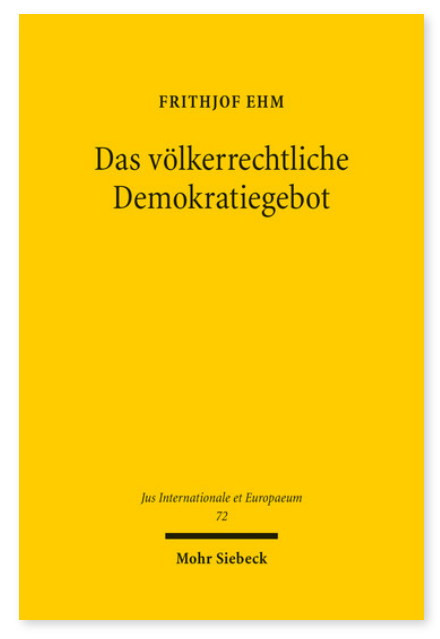

2013. XXIX, 359 Seiten. JusIntEu 72

ISBN 978-3-16-152299-4

DOI 10.1628/978-3-16-152299-4

eBook PDF $89,00 €$

ISBN 978-3-16-152039-6

fadengeheftete Broschur $89,00 €$
Internationale Studien belegen, dass sich die Staats- und Regierungsform der Demokratie in den letzten Jahren weltweit zunehmend verbreiten konnte. Diese Entwicklung hat Frithjof Ehm zum Anlass genommen, eine kaum noch zu überschauende Anzahl an Verträgen, Erklärungen und vielen weiteren einschlägigen Dokumenten mit Bezug zur demokratischen Verfasstheit von Staaten zu untersuchen. Dabei kommt er zu dem Ergebnis, dass sowohl dem Völkervertragsrecht als auch dem Völkergewohnheitsrecht ein an die Staaten gerichtetes Demokratiegebot entnommen werden kann. Der Autor beschränkt diesen neuen völkerrechtlichen Rechtssatz jedoch auf elementare Kernelemente und macht inn damit praktikabel. Anschließend beschäftigt er sich mit der Frage, welche völkerrechtliche Bedeutung das Demokratiegebot für den Staat und auch das Völkerrecht selbst besitzt. Mit dieser Arbeit leistet Frithjof Ehm einen wichtigen Beitrag zum Wandel des Völkerrechts hin zu einer immer mehr wertgebundenen internationalen Rechtsordnung.

Frithjof Ehm Geboren 1981; Studium der Rechtswissenschaften in Mannheim, Göttingen und Dublin (Trinity College); Ergänzungsstudiengang »Rechtsintegration in Europa« (MLE.); 2008-10 wissenschaftlicher Mitarbeiter einer internationalen Wirtschaftskanzlei; 2011 Promotion an der Bucerius Law School in Hamburg; 2012 Zweite Juristische Staatsprüfung vor dem Landesjustizprüfungsamt Celle.
Jetzt bestellen:

https://mohrsiebeck.com/buch/das-voelkerrechtliche-demokratiegebot-9783161522994?no_cache=1

order@mohrsiebeck.com

Telefon: +49 (0)7071-923-17

Telefax: +49(0)7071-51104 